\section{Stickler syndrome, ocular-only variants and a key diagnostic role for the ophthalmologist}

\begin{abstract}
The entity described by Gunnar Stickler, which included hereditary arthroophthalmopathy associated with retinal detachment, has recently been recognised to consist of a number of subgroups, which might now more correctly be referred to as the Stickler syndromes. They are the most common clinical manifestation of the type II/XI collagenopathies and are the most common cause of inherited rhegmatogenous retinal detachment. This review article is intended to provide the ophthalmologist with an update on current research, subgroups, and their diagnosis together with a brief overview of allied conditions to be considered in the clinical differential diagnosis. We highlight the recently identified subgroups with a high risk of retinal detachment but with minimal or absent systemic involvement - a particularly important group for the ophthalmologist to identify.

Eye (2011) 25, 1389-1400; doi:10.1038/eye.2011.201; published online 16 September 2011
\end{abstract}

Keywords: collagen; COL2A1; COL11A1; Stickler syndrome; retinal detachment; vitreous

\section{Introduction}

The first report detailing hereditary arthroophthalmopathy, or Stickler syndrome as it quickly became known, was in $1965,{ }^{1}$ with a supplementary report 2 years later. ${ }^{2}$ The syndrome is an hereditary connective tissue disorder of fibrillar collagen associated with congenital megalophthalmos, retinal detachment, deafness, cleft palate, Pierre-Robin sequence, joint hypermobility, and premature arthritis. Initially considered a monogenic disorder (and possibly allelic with Wagner
MP Snead ${ }^{1,2}$, AM McNinch $^{1,3}$, AV Poulson ${ }^{1,2}$, P Bearcroft ${ }^{2}$, B Silverman ${ }^{2}$, P Gomersall ${ }^{2}$, V Parfect ${ }^{2}$ and AJ Richards ${ }^{1,3}$ vitreoretinopathy - see below), it has now emerged as the most common manifestation from the spectrum of type II/XI collagenopathies, which also includes spondyloepiphyseal dysplasia congenita (SEDC), Kniest dyplasia, metatropic dysplasia, and achondrogenesis type II. The last major review was in $1999^{3}$ and research over the last 10 years has brought much new information to light. The purpose of this article is, therefore, to bring the ophthalmologist up to date with an overview of the general systemic aspects of the disorder, differential diagnoses, and particularly the novel variations and subgroups with predominantly or exclusively ocular involvement. The ophthalmologist has a particularly important role in the identification and diagnosis of this latter group.

\section{Collagen: genetics and nomenclature}

The collagen family is the most abundant protein group found in animals and consists of a heterogeneous group of extracellular glycoproteins incorporating at least one triple helical domain as their signature motif. ${ }^{4}$

The three principal collagen types found in human vitreous are types II, IX, and XI. Mutations affecting the genes encoding all three of these fibrillar collagens are now known to cause Stickler syndrome, but the majority are due to defects in the major structural constituent, type II collagen.

All collagen molecules include a trimer of $3 \alpha$ peptide chains. These may be identical (homotrimer) as in type II collagen, constructed from three identical cords of type II collagen polypeptide chains. Alternatively, they may be different (heterotrimers) as in type XI collagen, which has three different constituent peptide chains. In either case, the amino-acid sequence in each of the $\alpha$ chains contributing to the triple
${ }^{1}$ Vitreoretinal Service, Molecular Genetics and Medical Genetics, Cambridge, UK

${ }^{2}$ Cambridge University NHS Foundation Trust, Cambridge, UK

${ }^{3}$ Department of Pathology, University of Cambridge, Cambridge, UK

Correspondence: MP Snead, Vitreoretinal Service, Cambridge University NHS Foundation Trust, Hills Road, Cambridge,

Cambridgeshire,

CB2 OQQ, UK

Tel: + 44 (0)1223 216701;

Fax: + 44 (0)1223 217968

E-mail:mps34@cam.ac.uk

Received: 2 March 2011

Accepted in revised form:

11 July 2011

Published online: 16

September 2011 
helix conforms to a highly conserved repeating triplet sequence, whereby glycine, the smallest amino acid, occupies every third position. This repeating motif is believed to be essential for correct trimerisation of the polypeptide chains during assembly of the triple helical domain and construction of the mature collagen molecule.

Convention dictates that the collagen types are designated by Roman numerals. In contrast, the genes encoding their constituent protein-building blocks are given Arabic numeral nomenclature, written (for human genes) in upper case. From this, it will be seen that type II collagen (a homotrimer) only has a single encoding gene, which is called COL2A1 (COL = collagen; $2=$ Type II, $\mathrm{A} 1=\alpha 1$ peptide) and whose locus is on the long arm of chromosome 12 .

In contrast, type XI collagen is formed as a heterotrimer of three different constituent chains each encoded by three different genes: COL11A1, COL11A2, and COL2A1 (the $\alpha(1)$ II peptide interestingly also forms part of the type XI molecule). Type IX collagen is also a heterotrimer formed by three different constituent chains encoded by three different genes: COL9A1, COL9A2, and COL9A3. Type XI is expressed in alternative forms in different tissues. While the $\alpha 1$ chain of type XI collagen is expressed in both ocular and cartilaginous tissue, the $\alpha 2$ chain is predominantly expressed in non-ocular (cartilage) tissue. Defects affecting this latter protein, therefore, result in an arthropathy with an unaffected or normal ocular phenotype, whereas defects affecting the former will result in 'full' Stickler syndrome affecting both ocular and skeletal organisation.

In the extracellular matrix, collagen molecules assemble to form heterotypic (composed of more than one collagen type) fibrils. In vitreous, the collagen fibrils are composed mainly of type II collagen molecules organised around a core of type XI collagen. These type II/XI collagen fibrils are connected to other components of the extracellular matrix in part by type IX collagen, a member of the FACIT (fibril associated collagens with interrupted triple héelices) collagens.

\section{Stickler syndrome}

First described in $1965,^{1,2}$ hereditary arthroophthalmopathy (Stickler syndrome) is now known to encompass at least five clinically different subgroups, ${ }^{5-11}$ which are summarised in Table 1, and in addition there is still further genetic heterogeneity to be resolved. ${ }^{12,13}$ The group forms one of the most prevalent of the connective tissue disorders - the service in Cambridge now seeing an average of one and half new families per week and with nearly 1000 Stickler syndrome patients registered on the Vitreoretinal Service database.

The majority of cases seen by ophthalmologists will be type 1 Stickler syndrome, which is inherited in an autosomal dominant fashion. However, an important key point to note is that a significant minority results from de novo mutations so that there will be no diagnostic indicator from an associated family history. Furthermore, the ocular-only variants will have minimal or no associated systemic features to alert the clinician to the possible diagnosis ${ }^{10,11}$ and so the clinician should retain a high index of suspicion even in the absence of these associated features.

\section{Diagnosis}

Until the relatively recent provision of routine molecular genetic analysis, the diagnosis was wholly reliant on the combination of major and minor clinical diagnostic criteria. ${ }^{14}$ Clinical assessment continues to have a vital role as an indicator of clinical suspicion and also to assist in indicating which genes to screen. ${ }^{15}$

For the ophthalmologist, combining clinical and molecular genetic analysis is particularly important given the emerging array of ocular-only variants ${ }^{10,11}$ (see below) with a high risk of retinal detachment, but

Table 1 Subgroups of Stickler syndrome

\begin{tabular}{|c|c|c|c|}
\hline Type & Gene & Distinguishing features & Reference \\
\hline Type 1 & COL2A1 & $\begin{array}{l}\text { Membranous congenital vitreous anomaly, congenital megalophthalmos, deafness, } \\
\text { arthropathy, cleft palate. }\end{array}$ & 5 \\
\hline Type 2 & COL11A1 & $\begin{array}{l}\text { Beaded congenital vitreous anomaly, congenital megalophthalmos, deafness, arthropathy, } \\
\text { cleft palate. }\end{array}$ & 6 \\
\hline Type 3 & COL11A2 & Normal vitreous and ocular phenotype, deafness, arthropathy, cleft palate. & 7 \\
\hline Type 4 & $\begin{array}{l}\text { COL9A1 } \\
\text { COL9A2 }\end{array}$ & $\begin{array}{l}\text { Recessive inheritance, sensorineural deafness, myopia, vitreoretinopathy, epiphyseal } \\
\text { dysplasia. }\end{array}$ & 8,9 \\
\hline Ocular-only & COL2A1 & $\begin{array}{l}\text { Membranous congenital vitreous anomaly (usually), congenital megalophthalmos. } \\
\text { No systemic features. }\end{array}$ & 10,11 \\
\hline Other & Unknown & Hypoplastic vitreous, deafness, arthropathy, cleft palate. & 12,13 \\
\hline
\end{tabular}


which would be overlooked or excluded using diagnostic criteria constrained by the requirement of radiological or systemic involvement. ${ }^{16,17}$ Similarly, combined clinical and molecular genetic analysis allows identification of the non-ocular variants, which (from the ophthalmologists perspective) can be safely discharged without need for further investigation or follow-up. ${ }^{7}$

\section{Clinical features}

The phenotypic expression of Stickler syndrome will be manifest in four distinct areas: ocular, oro-facial, auditory, and musculoskeletal.

\section{Ocular}

The pathognomonic feature of Stickler syndrome is a congenital abnormality in vitreous embryological development, which is manifest as an abnormal architecture visible on slit lamp biomicroscopy. The four common phenotypes are shown in Figure 1. Examination of the vitreous is especially important for the clinical diagnosis of the ocular-only subgroups, which are only likely to present to an ophthalmologist. In addition to being a diagnostic hallmark, vitreous assessment has been used to guide molecular genetic analysis in a more efficient manner than blind screening of all candidate genes.
A protocol depicting the diagnostic flow chart and associated molecular genetic analysis ${ }^{15}$ is illustrated in Figure 2.

The majority of patients presenting to an ophthalmologist will have either type 1 or type 2 Stickler syndrome and are frequently myopic. ${ }^{18-20}$ The refractive error is characteristically congenital, of high degree, and is often associated with a significant astigmatic component. It is, however, important to be aware that in some series almost a quarter of patients exhibit no significant refractive error and so this cannot be depended upon as a reliable screening tool for exclusion.

The association with congenital cataract is well recognised, ${ }^{21,22}$ and some patients may exhibit a characteristic quadrantic lamellar cortical lens opacity, which, if present, can be a useful diagnostic sign (Figure 3). It does not, however, differentiate between subgroups, being present in both type 1 and type 2 Stickler syndrome.

In addition to the characteristic lens opacities, some patients will exhibit congenital abnormalities of the anterior chamber drainage angle, ${ }^{23-25}$ which may predispose them to a higher risk of glaucoma. Experience suggests, however, that this is a relatively uncommon finding and that in the majority of patients with glaucoma, this is a chronically progressive angle closure phenomenon resulting from retinal detachment and proliferative vitreoretinopathy causing secondary cellular angle occlusion.
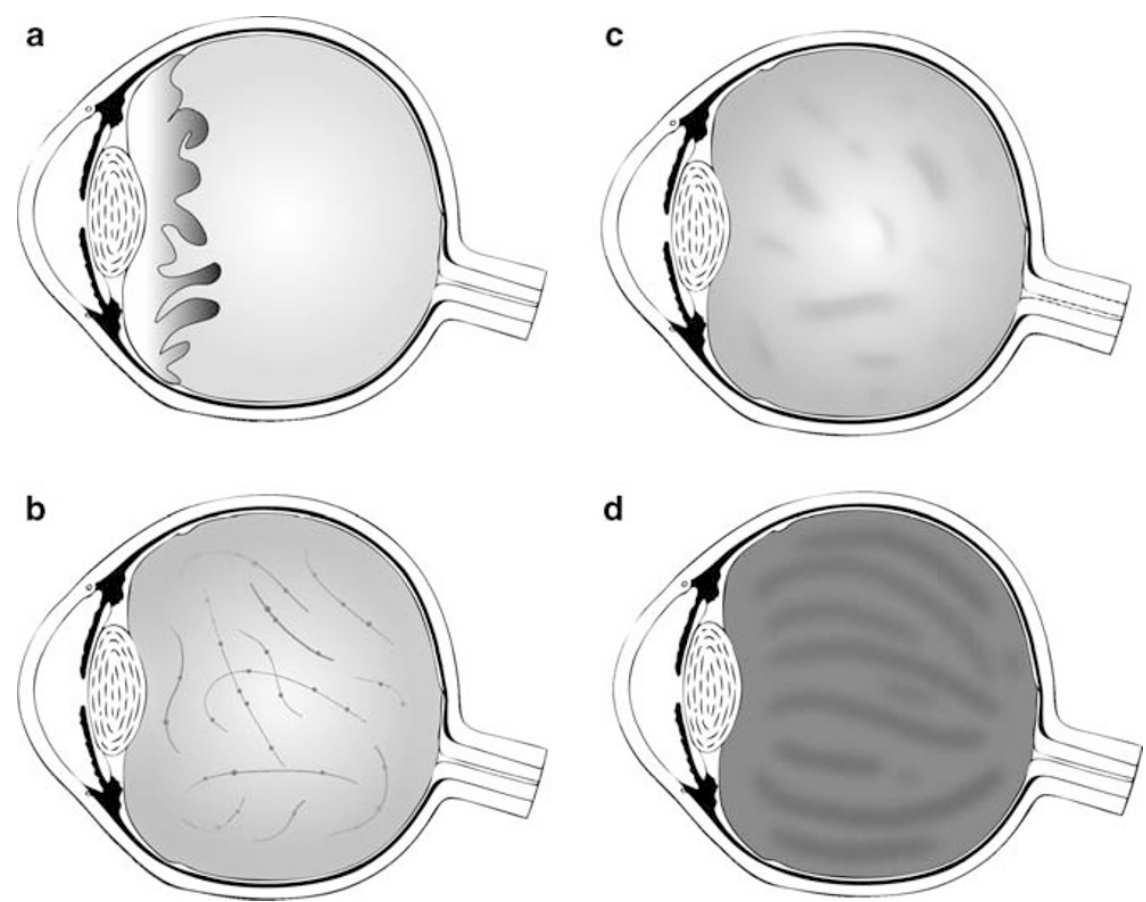

Figure 1 Schematic illustration of vitreous phenotypes. (a) (top left) Membranous congenital vitreous anomaly, (b) (bottom left) Beaded congenital vitreous anomaly, (c) (top right) Hypoplastic congenital vitreous anomaly, (d) (bottom right) Normal vitreous architecture: compact lamellar array. Reproduced with permission from Richards et al. ${ }^{15}$ 
MDT Assessment

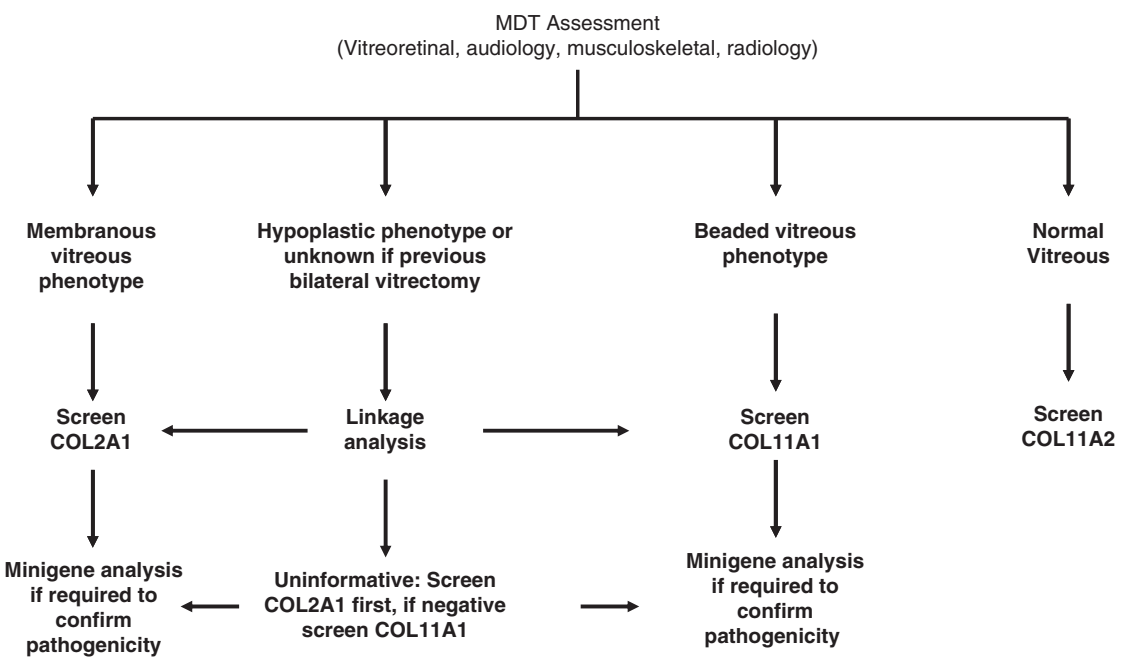

Figure 2 Algorithm for gene selection and mutation analysis in Stickler syndrome based on vitreous phenotype.
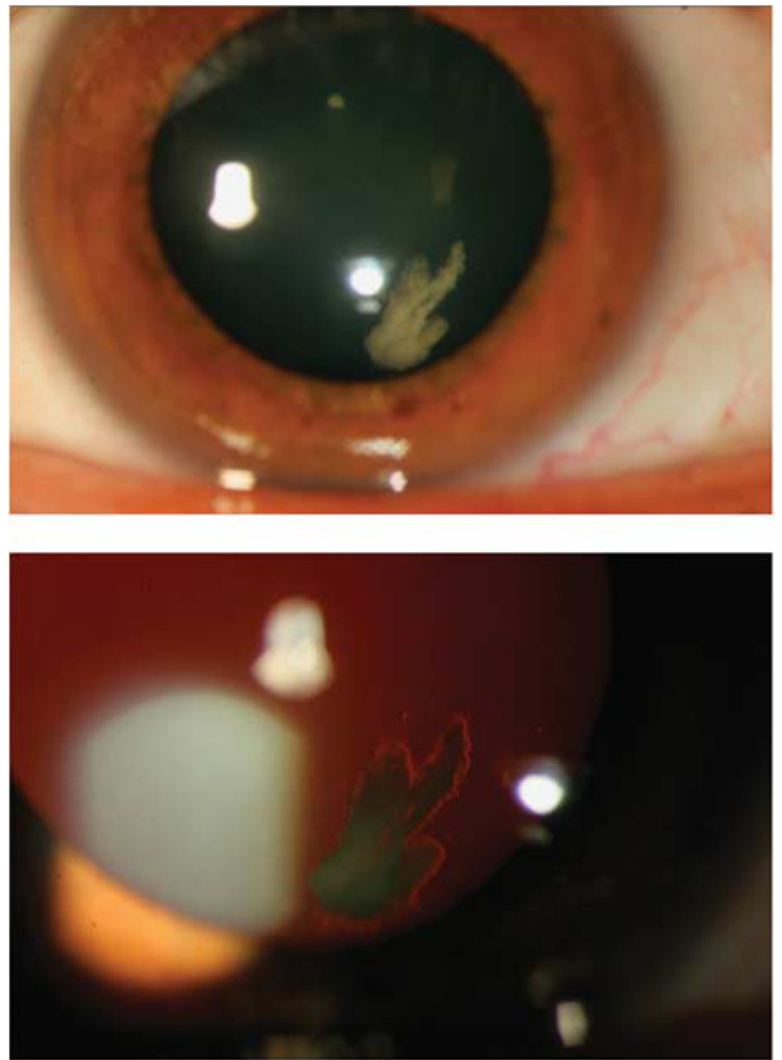

Figure 3 Congenital quadrantic lamellar cataract. Typical of Stickler syndrome, but does not differentiate between subtypes.

The risk of retinal detachment in Stickler syndrome is well known and highlighted in the original description. ${ }^{1,2}$ Surveys of unselected cohorts in both the United Kingdom and United States reported that over 50\% of patients with a clinical diagnosis of one of the Stickler syndromes had already suffered a retinal detachment, ${ }^{20}$ and in a large study of the genetically confirmed type 1 subgroup, this figure rose to over $70 \%$ of which almost half had bilateral detachment. ${ }^{26}$ The risk in type 2 Stickler syndrome appears to be slightly less but remains to be quantified, surveys suggesting that between $40-50 \%$ of patients had suffered detachment (Poulson $e t a l^{19}$ and unpublished data).

Patients with type 1 Stickler syndrome have a particularly high risk of developing retinal detachment as a result of a giant retinal tear (GRT), that is to say a circumferential break at the pars plana junction caused by a separation of the posterior hyaloid membrane (PHM) much more anteriorly than would normally be the case (Figure 4). In such instances (with or without GRT), the PHM will sit behind the pre-existing type 1 anomaly resulting in a double membrane (Figure 5). The clinician should also be alert to the possibility that posterior vitreous detachment in type 2 Stickler syndrome can result in the (single) detached posterior hylaloid membrane masquerading as the type 1 anomaly. Prophylactic retinopexy designed and positioned specifically to prevent GRT progression appears to substantially reduce the risk of retinal detachment and blindness from this type of break in type 1 Stickler syndrome. ${ }^{26}$ Detachment due to more posterior breaks can occur but is impossible to predict in terms of position, making effective prophylaxis in all cases impractical.

\section{Oro-facial}

All subgroups of Stickler syndrome with systemic involvement may exhibit clefting abnormalities of the hard or soft palate. This is distinct from other causes of 


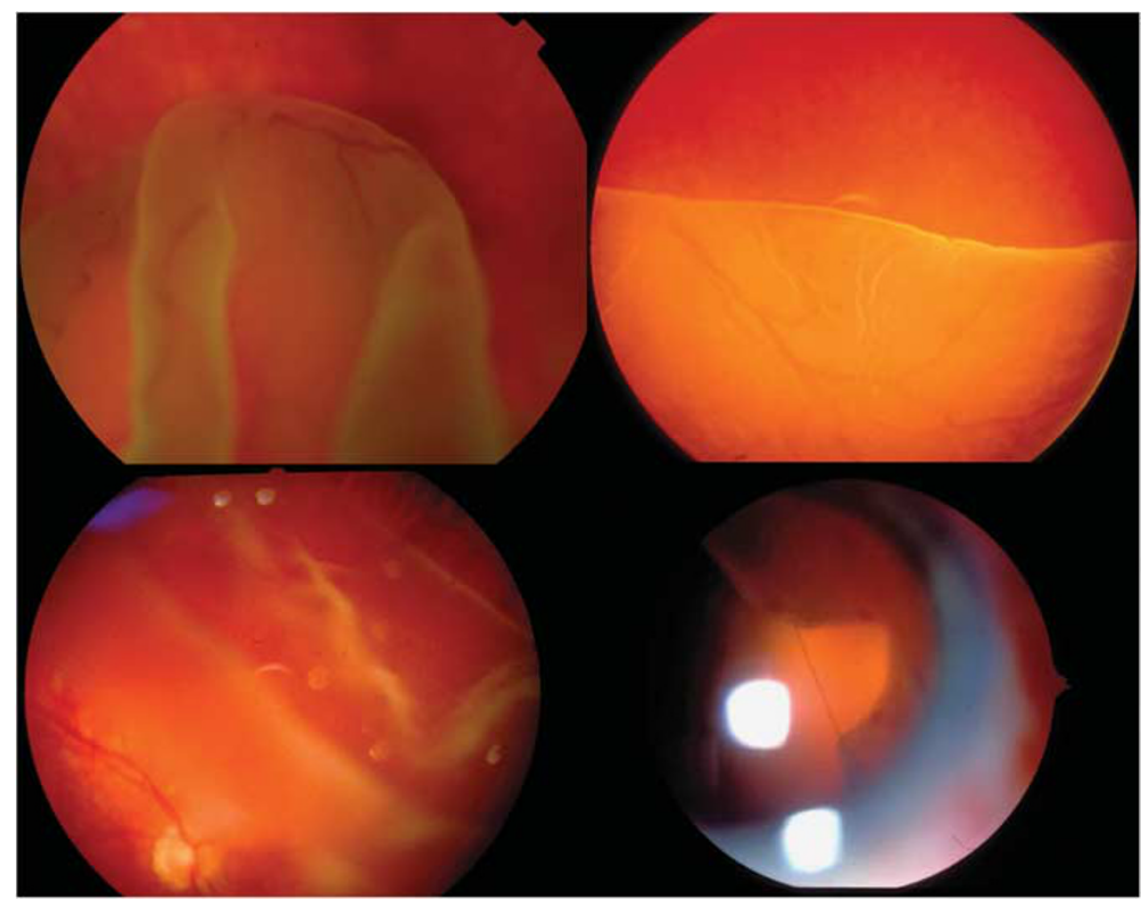

Figure 4 Giant retinal tears in patients with type 1 Stickler syndrome.

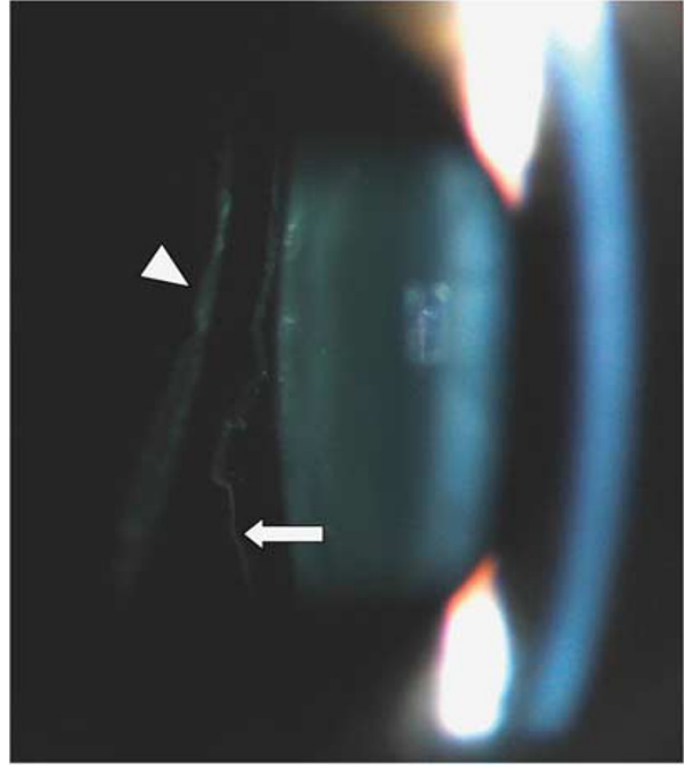

Figure 5 Posterior vitreous detachment in type 1 Stickler syndrome. Posterior hyaloid membrane (PHM) (arrow head) visible as a second membrane behind type 1 congenital membranous vitreous anomaly (arrow). In type 2 Stickler syndrome, the ophthalmologist should be wary of mistakenly confusing PHM with type 1 anomaly-examination of fellow eye may help.

midline clefting associated with cleft lip, the latter feature not being associated with Stickler syndrome. Abnormalities of the hard and soft palate are frequently associated with impairment of eustachian tube function

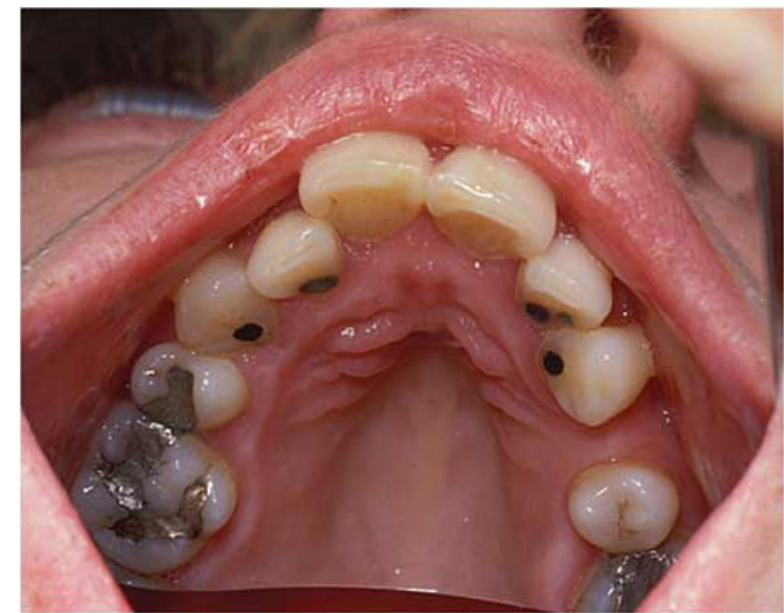

Figure 6 Subclinical midline cleft in type 1 Stickler syndrome. The patient was unaware of their palate abnormality.

and middle ear impairment (see below), and in those patients without a history of palate repair, direct examination and palpation will help identify those with subclinical clefts (Figure 6) - another helpful diagnostic sign for the clinician, but easily overlooked.

\section{Auditory features}

Hearing loss in Stickler syndrome is well documented but its pathogenesis is not fully understood. Audiometric thresholds (a measure of the quietest sounds an individual can hear) across subgroups of both type 1 and 
type 2 Stickler are frequently increased when compared with age-related controls. The severity of the loss is widely reported to be worse in the non-ocular cases (type $3,{ }^{7}$ harbouring COL11A2 mutations). A differential may also exist in type 1 Stickler syndrome where hearing loss is restricted more specifically to high-frequency sound perception, as opposed to a flatter audiometric profile found in type 2 cases. ${ }^{27}$

Irrespective of subtype, comparing the degree of hearing impairment between individuals indicates a large variation ranging from no impairment to profound hearing loss, which may be due to (i) conductive loss - affecting the mechanisms by which sound waves are transferred from the air into the cochlear fluids, (ii) sensorineural loss - affecting the transduction of mechanical vibrations into action potentials within the cochlear or the subsequent transmission of neural information in the auditory nerve and central nervous system, or (iii) mixed - a combination of (i) and (ii). ${ }^{27}$

In addition to the raised hearing thresholds, abnormal tympanic membrane mobility (measured using tympanometry) has been observed in individuals identified with Stickler syndrome, although interestingly this is not always linked to a conductive hearing loss. ${ }^{27}$ Tympanic membrane defects are perhaps not surprising given the presence of type II collagen within the membrane structure within the two fibrous middle layers. $^{28}$

Sound energy absorbed by the tympanic membrane is passed into the three middle ear ossicles. Type II collagen is known to be present in the articular joints between these middle ear bones, and it is possible that defects of the collagen within these joints could be associated with conductive hearing impairment and could also contribute to the large number of hypermobile tympanograms that have been reported in one study focusing primarily on type 1 individuals. ${ }^{27}$ Our own studies of type 2 Stickler syndrome suggest far fewer incidences of hypermobility (unpublished data). In addition, the associated cranio-facial abnormalities may significantly increase the risk of otitis media. As a consequence, conductive hearing loss may result (i) from recurrent otitis media permanently damaging the tympanic membrane and/or ossicles, (ii) directly from the primary collagen defect, (iii) from adverse healing following on from previous intervention such as grommets, or (iv) from a combination of the above.

Sensorineural hearing loss is associated with mutations of both COL11A1 and COL11A2, and expression of these genes has been identified in the developing cochlea. ${ }^{29}$ It has been suggested that these mutations affect the structure of the cochlear, particularly the mechanical properties of the cochlear partition.
It is clear, therefore, that audiometric data may be valuable in assessing an individual with suspected Stickler syndrome, but findings must be interpreted with care. In the type 1 group, the hearing loss is often mild and of high frequency (one study suggests that $60 \%$ of individuals were documented with this form of loss), which may be difficult to distinguish from age-related and noise-induced hearing loss. In addition, temporary conductive hearing impairments are extremely common in the young, and widely associated with cranio-facial abnormalities of a variety of aetiologies. The hearing loss in type 2 cases may be more readily identifiable, with suggestions that sensorineural hearing loss is more common and the audiometric profile is 'flatter' (affecting lower frequencies), and therefore more unusual.

The association between abnormally mobile tympanic membranes and collagen defects is theoretically sound, but has not been widely seen in our type 2 cohort. Care must be taken to tease apart an individual's history of ear infections and ENT intervention when tympanometry highlights these abnormalities. Otoscopic examination of the tympanic membrane may reveal areas of thinning due to previous trauma. Cautiously, it might be considered that the recording of hypermobile tympanometry traces with a tympanic membrane absent of any signs of trauma and in the absence of a history of recurrent otitis media/ENT intervention/head impact might suggest a Stickler-type collagen disorder affecting the ossicular chain, ${ }^{30}$ although there are other possible causes.

\section{Musculoskeletal}

More than $80 \%$ of children and adults with a diagnosis of Stickler syndrome report musculoskeletal symptoms, which have a considerable impact on their quality of life. ${ }^{20}$ There are wide variations in the clinical manifestations, none of which is unique to the Stickler syndromes. Nearly $90 \%$ of patients have spinal abnormalities (flattened vertebrae, end plate changes, scoliosis, and/or kyphosis, only rarely requiring surgery) with $85 \%$ of adults reporting chronic back pain. ${ }^{31}$ Some children have bony joint enlargement due to epiphyseal dysplasia. Joint hypermobility is common ${ }^{16,31}$ and although it may be asymptomatic it can lead to knock knees, flat feet, joint subluxation or dislocation, and widespread joint pain. Stickler patients are occasionally given an erroneous diagnosis of Perthes disease as the appearances in some patients are similar radiologically. It is also common for adolescent Stickler syndrome patients to receive a diagnosis of Osgood Schlatters disease ${ }^{32}$ but as this is a clinical rather than a radiological diagnosis (and that it is common in adolescence generally to have 
anterior tibial pain) the true nature of this association remains to be clarified.

Hypermobility becomes clinically less apparent with age. Premature osteoarthritis, often symptomatic by the third or fourth decade, may develop in patients with or without preceding joint hypermobility. The prevalence of joint pain increases to more than $90 \%$ by the fifth decade. $^{33}$

\section{Genetics and molecular mechanisms for phenotypic variation}

The majority of patients presenting to the ophthalmologist will have type 1 Stickler syndrome and this subgroup accounts for almost 700 of the cases assessed as part of the Cambridge service. Most are due to premature termination or frame-shift mutations of the COL2A1 gene resulting in haploinsufficiency and under production of type II collagen. However, the disorder is known to exhibit a wide degree of intra- and inter-familial variation, and a key recent finding for ophthalmologists is the emerging subgroups of patients with minimal or no systemic features and an 'ocular-only' phenotype.

To date, five principle molecular mechanisms have been identified, which can result in an atypical phenotype, the most important of which (for ophthalmologists) are the ocular-only variants. Without systemic involvement, this latter group is frequently mis-diagnosed or undiagnosed altogether until retinal detachment presents.

Phenotypic variation can result from:

(i) Alternatively spliced exons. ${ }^{10,34,35}$

(ii) Splice site mutations resulting in alternatively spliced transcripts. ${ }^{11}$

(iii) Differential effects of various amino-acid substitutions. ${ }^{36}$

(iv) Mosaicism: Although apparently isolated cases of COL2A1-associated diseases may be caused by de novo mutations, a report highlights the role of mosaicism as a fifth possible cause, which should be considered for phenotypic variation in COL2A1 disorders. $^{37}$

(v) Compound Heterozygosity. ${ }^{38}$

In addition to assisting the clinical diagnosis, the diagnostic protocol depicted in Figure 2 assists and directs mutation analysis substantially improving COL2A1 analysis resulting in a 95\% positive pick-up rate. ${ }^{15,39}$ The advances currently being made in sequencing technologies, so-called next-generation sequencing, may in future make it more economically viable to sequence and analyse all candidate genes simultaneously; however, at present, the vitreous phenotyping before molecular analysis greatly increases the efficiency of mutation detection.

\section{Differential diagnosis of allied connective tissue vitreoretinopathies}

Using the four principal clinical features as a filtering sieve should alert the clinician to the possibility of Stickler syndrome or allied connective tissue disorder. The Stickler syndromes form by far the biggest subgroup of these, but other rarer variants (usually accompanied by more severe skeletal dysplasia) are summarised briefly below for the ophthalmologist.

\section{Spondyloepiphyseal dysplasia congenita}

SEDC presents at birth with shortening of the trunk and proximal (rhizomelic) limbs - the hands and feet appearing relatively normal. In common with the other type II/XI collagenopathies, it may be associated with hearing loss (both conductive and sensorineural) and cleft palate. Odontoid hypoplasia may be associated with atlanto-axial instability and should be borne in mind, particularly for patients undergoing general anaesthesia. It is typically caused by dominant negative mutations in COL2A1, resulting in glycine substitutions in the $\alpha-1$ type II collagen polypeptide.

\section{Spondyloperipheral dysplasia}

Spondyloperipheral dysplasia is a variant of the spondyloepiphyseal dysplasias, but with distal limb shortening, midface hypoplasia, congenital high myopia, platyspondyly, and brachydactyly. ${ }^{40,41}$ It is caused by mutations in the $\alpha-1$ type II collagen gene COL2A1.

\section{Kniest dysplasia}

Kniest dysplasia is a dominantly inherited disorder of type II collagen similar to SEDC, but with more severe and generalised skeletal manifestations (Figure 7). The association with cleft palate is shared with the other type II collagenopathies, but patients exhibit a shortened trunk and limbs with expanded dumbbell-like flaring of the metaphysis. Major problems result from progressive joint enlargement and contracture, especially affecting the metacarpophalangeal and phalangeal joints. Hearing loss (both conductive and sensorineural) is common.

\section{Otospondylomegaepiphyseal dysplasia (OSMED)}

Although expressed in both cartilage and vitreous, type XI collagen is a heterotrimer of three different polypeptide chains: $\alpha 1(\mathrm{XI}), \alpha 2(\mathrm{XI})$, and $\alpha 3(\mathrm{XI})$. The $\alpha 3$ 


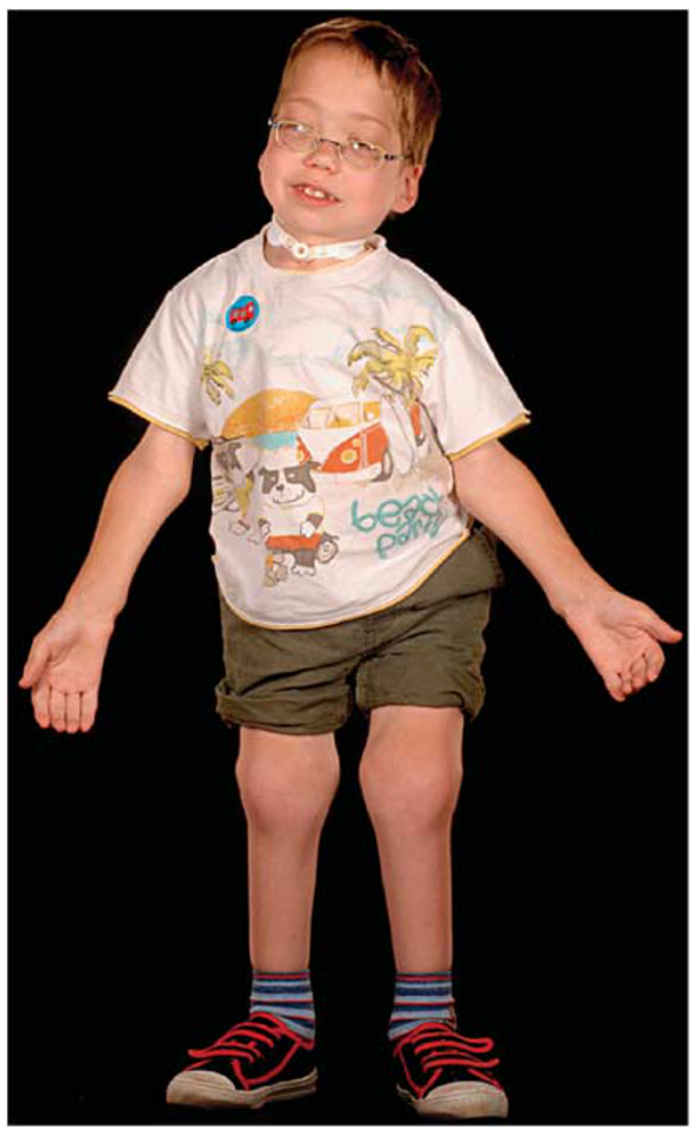

Figure 7 Kniest dysplasia. Note severe arthropathy and characteristic interphalangeal epiphyseal dysplasia. chain of type XI collagen is actually transcribed from the COL2A1 gene, and in vitreous, the second polypeptide $\alpha 2(\mathrm{XI})$ is replaced by the $\alpha 2$ chain of type $\mathrm{V}$ collagen.

Mutations affecting the COL11A2 gene, therefore, do not affect the eye and result in a normal vitreous phenotype (Figure 1d) with arthropathy and deafness, and was originally designated as Stickler syndrome type III or 'non-ocular' Stickler syndrome (MIM 184840). Since Stickler syndrome, as originally reported, was an ocular disorder associated with an arthropathy, this classification can be confusing and the condition is sometimes now referred to as OSMED or Weissenbacher-Zweymuller syndrome. ${ }^{42,43}$

\section{Other non-type II/XI collagenopathies}

\section{Knobloch syndrome}

Knobloch syndrome is a recessive disorder of type XVIII collagen first described in $1971^{44}$ as an association between vitreoretinopathy and occipital encephalocoele (Figure 8). Other features include unusual palmer creases, nail hypoplasia, dental caries, and (in one patient) spina bifida.

Molecular genetic analysis most commonly implicates homozygous splice site changes in the gene encoding the $\alpha 1$ chain of type XVIII collagen (COL18A1), although compound heterozygotes have also been identified.

The gene locus is on the long arm of chromosome 21 and encompasses 41 exons and is expressed in two distinct

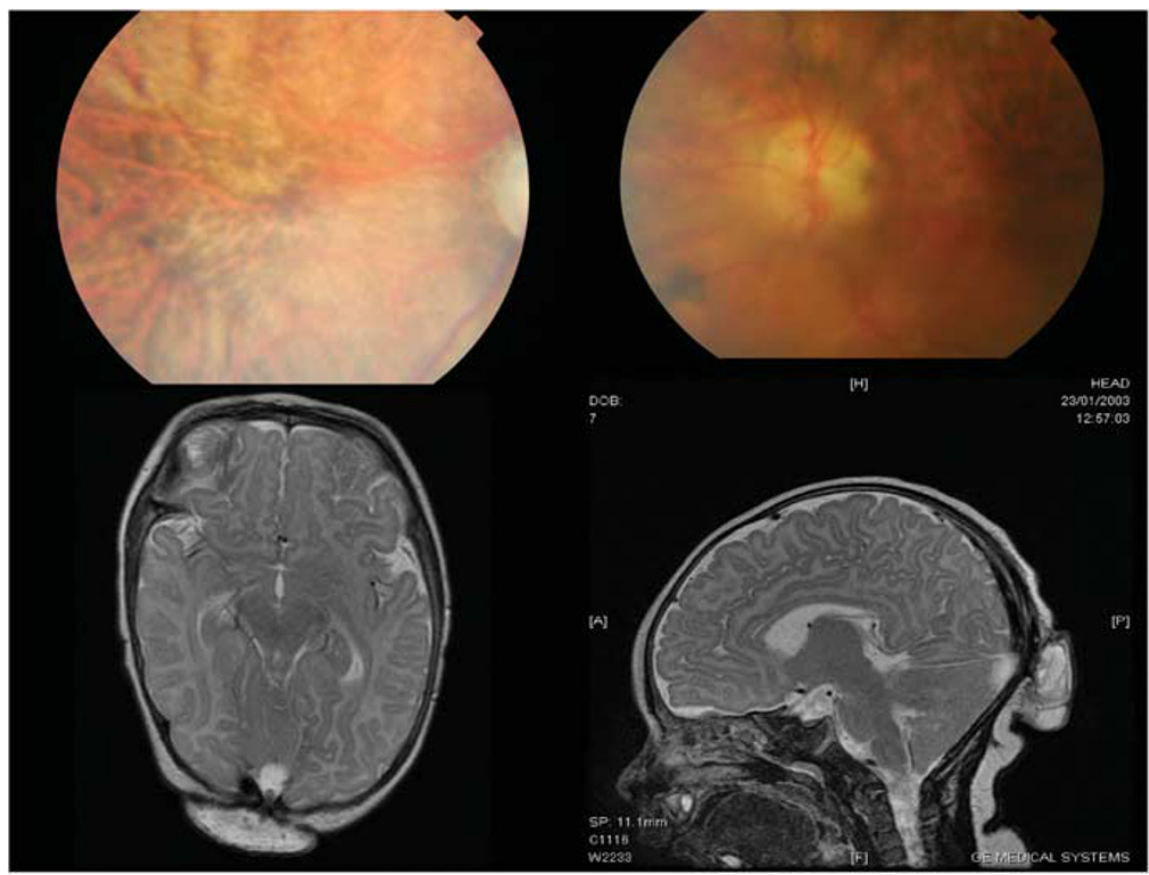

Figure 8 Occipital encephalocoele in Knobloch syndrome-a type XVIII collagenopathy associated with vitreoretinopathy and retinal detachment. Left inferior macular off retinal detachment. 
isoforms, the longer isoform being expressed in adult retina and may have a role in retinal structure, as well as in the closure of the neural tube. It is also highly expressed in the kidney and the liver, but no patients reported have exhibited any major kidney or liver defects. ${ }^{45,46}$

\section{Wagner syndrome}

At one time considered synonymous with the 'ocularonly' varieties of Stickler syndrome, ${ }^{47}$ this disorder is now known to be a clinically and genetically separate entity. ${ }^{48,49}$ The principal features include markedly subnormal rod and cone responses on ERG, accelerated premature cataract, chronic flare and uveitis without synechia, pseudo exotropia (Figure 9), progressive hemeralopia, retinal detachment, and a progressive, and ultimately extensive, erosive vitreoretinopathy. ${ }^{50}$

Molecular genetic analysis reported to date implicates CSPG2, the gene encoding Versican, ${ }^{49,50}$ a large chondroitin sulphate proteoglycan and a member of a family of glycoproteins first identified in hyaline cartilage, which interact with hyaluronan to form large supramolecular complexes providing mechanical support. Versican is part of a subgroup of such molecules that exist also in a variety of soft tissues, and via alternative splicing generates four major variants VO, V1, V2, and V3. In Wagner syndrome, mutations have so far all affected splicing of exon 8 , which is present in the V0 and V1 isoforms. ${ }^{51}$ Presumably, the domain encoded by this exon is essential for normal ocular development but is not as important in other tissues.

\section{Multiple epiphyseal dysplasia (MED)}

MED presents in childhood as an arthropathy associated with abnormal gait and hip pain with Perthes disease

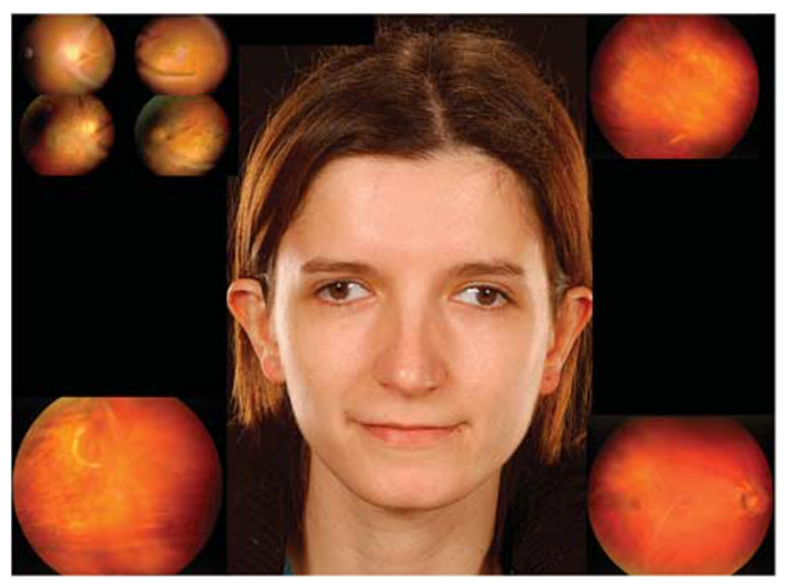

Figure 9 Pseudo exotropia in Wagner syndrome. Reproduced with permission from Meredith et al. ${ }^{50}$ (avascular necrosis of the femoral epiphysis). Genetic analysis has implicated mutations in cartilage oligomeric matrix protein, matrillin 3 , and the genes for type IX collagen, COL9A1, COL9A2, and COL9A3. In most instances, of MED the ocular phenotype is reported as normal. As type IX collagen is normally expressed in vitreous and there have been recent reports of autosomal recessive Stickler syndrome secondary to compound heterozygote mutations in $C O L 9 A 1,{ }^{8,9}$ the clinician should be alert to the theoretical possibility of ocular involvement with MED.

\section{Metatropic dysplasia}

Metatropic dysplasia is an autosomal recessive disorder ${ }^{52}$ whose name derives from the change or reversal in body proportions by a tendency for the associated dwarfism to change from short limbed to short trunked during infancy with subsequent progressive kyphoscoliosis. Although the head and face are usually normal, individuals can still exhibit megalophthalmos and thin sclera despite normal compact vitreous architecture. Recent research has identified compound heterozygous changes in the TRPV4 gene (12q24.1).

\section{Conclusions}

Stickler syndrome comprises a group of relatively common inherited connective tissue disorders associated with a very high risk of rhegmatogenous retinal detachment. Molecular genetic diagnosis is now routinely available for the majority of cases, and this review is intended to bring the ophthalmologist up to date with the major six subgroups, current research, and a brief overview of allied disorders as part of the clinical differential diagnosis.

Key points in both clinical assessment and molecular genetic analysis are as follows:

\section{Clinical assessment}

(1) Approximately $20 \%$ of patients are not myopic.

(2) Oral clefting may be asymptomatic - examination of palate is an important and can be an useful diagnostic sign.

(3) An audiogram may reveal subclinical hearing loss and differentiate conductive from sensorineural components.

(4) Radiographs of hips, lumbar spine, and knees may demonstrate features characteristic of Stickler syndrome not evident clinically, but interpretation of these may require the assistance of a 
radiologist with specialist expertise in skeletal dysplasias.

(5) Examination of parents and siblings may assist clinical assessment of a neonate or very young patient in whom vitreous assessment is difficult.

(6) The ophthalmologist has a key role to have in identifying and diagnosing the 'ocular-only' variants.

(7) Type 1 Stickler syndrome has a high risk of retinal detachment and blindness from giant retinal tear, and prophylaxis should be considered and discussed with patients and parents to reduce this risk.

\section{Molecular genetic diagnosis}

Considerable progress has been made over the last 20 years in the molecular genetic diagnosis of Stickler syndrome, summarised as follows:

(1) First COL2A1 mutation in type 1 Stickler syndrome was identified in 1991.

(2) COL2A1 mutation in the original Stickler kindred was identified in 1996.

(3) First COL11A1 mutation in type 2 Stickler syndrome was identified in 1996.

(4) Mechanisms 'ocular-only' phenotypes were highlighted in 2000-2006.

(5) First COL9A1 report of AR Stickler syndrome 2006.

(6) Molecular genetic analysis now routinely available with a $95 \%$ positive pick-up rate 2010 .

The ophthalmologist should maintain a high index of clinical suspicion, particularly in the following scenarios:

(i) Neonates with Pierre-Robin/cleft and myopia.

(ii) Infants with spondyloepiphyseal dysplasia associated with myopia or deafness.

(iii) Patients with a family history of retinal detachment.

(iv) Sporadic cases of retinal detachment associated with joint hypermobility, midline clefting, or deafness.

\section{Conflict of interest}

The authors are commissioned by The Advisory Group for National Specialised Services (www.specialisedservices.nhs.uk) and the Department of Health to provide a national diagnostic service for Stickler syndrome.

\section{Acknowledgements}

This work was supported in part by grants from The Isaac Newton Trust, The Guide Dogs for the Blind Association, Action Medical Research, The Evelyn Trust, and the University of Cambridge. In addition, we wish to thank Gill Whitmore, The Stickler Syndrome Support Group, and Edwina Mort for helpful advice and assistance.

Useful contacts

http:/ / www.specialisedservices.nhs.uk

http:/ / www.stickler.org.uk

http:/ / www.vitreoretinalservice.org

\section{References}

1 Stickler GB, Belau PG, Farrell FJ, Jones JD, Pugh DG, Steinberg AG et al. Hereditary progressive arthroophthalmopathy. Mayo Clin Proc 1965; 40: 433-455.

2 Stickler GB, Pugh DG. Additional observations on vertebral anomalies, a hearing defect, and a report of a similar case. Mayo Clin Proc 1967; 42: 495-500.

3 Snead MP, Yates JR. Clinical and molecular genetics of Stickler syndrome. J Med Genet 1999; 36: 353-359.

4 Exposito J-Y, Valcourt U, Cluzel C, Lethias C. The fibrillar collagen family. Int J Mol Sci 2010; 11: 407-426.

5 Ahmad NN, Ala-Kokko L, Knowlton RG, Jimenez SA, Weaver EJ, Maguire JL et al. Stop codon in the procollagen gene (COL2A1) in a family with the Stickler syndrome (arthro-ophthalmopathy). Proc Natl Acad Sci USA 1991; 88: 6624-6627.

6 Richards AJ, Yates JR, Williams R, Payne SJ, Pope FM, Scott JD et al. A family with Stickler syndrome type 2 has a mutation in the COL11A1 gene resulting in the substitution of glycine 97 by valine in alpha 1 (XI) collagen. Hum Mol Genet 1996; 5: 1339-1343.

7 Sirko-Osadsa DA, Murray MA, Scott JA, Lavery MA, Warman ML, Robin NH. Stickler syndrome without eye involvement is caused by mutations in COL11A2, the gene encoding the alpha2(XI) chain of type XI collagen. J Pediatr 1998; 132: 368-371.

8 Van Camp G, Snoeckx RL, Hilgert N, van den Ende J, Fukuoka $\mathrm{H}$, Wagatsuma $\mathrm{M}$ et al. A new autosomal recessive form of Stickler syndrome is caused by a mutation in the COL9A1 gene. Am J Hum Genet 2006; 79: 449-457.

9 Baker S, Booth C, Fillman C, Shapiro M, Blair MP, Hyland JC et al. A loss of function mutation in the COL9A2 gene cause autosomal recessive Stickler syndrome. Am J Med Genet A 2011; 155(7): 1668-1672.

10 Richards AJ, Martin S, Yates JRW, Baguley DM, Pope FM, Scott JD et al. COL2A1 exon 2 mutations: relevance to the Stickler and Wagner syndromes. Br J Ophthalmol 2000; 84: 364-371.

11 Richards AJ, Snead MP. The influence of pre-mRNA splicing on phenotypic modification in Stickler's syndrome and other type II collagenopathies. Eye 2008; 22: 1243-1250.

12 Martin S, Richards AJ, Yates JR, Scott JD, Pope M, Snead MP. Stickler syndrome: further mutations in COL11A1 and evidence for additional locus heterogeneity. Eur J Hum Genet 1999; 7: 807-814.

13 Wilkin DJ, Mortier GR, Johnson CL, Jones MC, de Paepe A, Shohat $\mathrm{M}$ et al. Correlation of linkage data with phenotype in eight families with Stickler syndrome. Am J Med Genet 1998; 80: 121-127.

14 Snead MP, Payne SJ, Barton DE, Yates JR, Al-Imara L, Pope FM et al. Stickler syndrome: correlation between vitreoretinal phenotypes and linkage to COL2A1. Eye 1994; 8: 609-614. 
15 Richards AJ, McNinch A, Martin H, Oakhill K, Rai H, Waller $\mathrm{S}$ et al. Stickler syndrome and the vitreous phenotype: mutations in COL2A1 and COL11A1. Hum Mutat 2010; 31: E1461-E1471.

16 Rose PS, Levy HP, Liberfarb RM, Davis J, Szymko-Bennett Y, Rubin BI et al. Stickler syndrome: clinical characteristics and diagnostic criteria. Am J Med Genet 2005; 138A(3): 199-207.

17 Robin NH, Moran RT, Warman M, Ala-Kokko L. In: Pagon RA, Bird TC, Dolan CR, Stephen K (eds). GeneReviews [Internet]. University of Washington: Seattle (WA), 1993-2000.

18 Snead MP. Retinal detachment in childhood. In: Taylor D, Hoyt C (eds). Paediatric Ophthalmology and Strabismus. Blackwell Scientific Publications: Oxford, 2005, pp 595-605.

19 Poulson AV, Hooymans J, Richards AJ, Bearcroft P, Murthy R, Baguley D et al. Clinical features of Type 2 Stickler syndrome. J Med Genet 2004; 41: e107, (http:// www.jmedgenet.com/cgi/content/full/41/8/e107. ).

20 Stickler GB, Hughes W, Houchin P. Clinical features of hereditary progressive arthro-ophthalmopathy (Stickler syndrome): a survey. Genet Med 2001; 3: 192-196.

21 Scott JD. Prevention and perspective in retinal detachment. Duke Elder lecture. Eye 1989; 3: 491-515.

22 Seery CM, Pruett RC, Liberfarb RM, Cohen BZ. Distinctive cataract in Stickler syndrome. Am J Ophthalmol 1990; 110: 143-148.

23 Nielson CE. Stickler's syndrome. ACTA Ophthalmol 1981; 59: $286-295$

24 Spallone A. Stickler's syndrome: a study of 12 families. Br J Ophthalmol 1987; 71: 504-509.

25 Ayme S, Preus M. The Marshall and Stickler syndromes: objective rejection of lumping. J Med Genet 1984; 21 : 34-38.

26 Ang A, Poulson AV, Goodburn SF, Richards AJ, Scott JD, Snead MP. Retinal detachment and prophylaxis in type 1 Stickler syndrome. Ophthalmology 2008; 115: 164-168.

27 Szymko-Bennett YM, Mastroianni MA, Shotland LI, Davis J, Ondrey FG, Balog JZ et al. Auditory dysfunction in Stickler syndrome. Arch Otolaryngol Head Neck Surg 2001; 127: 1061-1068.

28 Knutsson J, Bagger-Sjbck D, von Unge M. Distribution of different collagen types in the rat's tympanic membrane and its suspending structures. Otol Neurotol 2007; 28: 486-491.

29 Shpargel KB, Makishima T, Griffith AJ. Col11a1 and col11a2 mRNA expression in the developing mouse cochlea: implications for the correlation of hearing loss phenotype with mutant type XI collagen genotype. Acta Otolaryngol 2004; 124: 242-248.

30 Baijens LW, De Leenheer EM, Weekamp HH, Cruysberg JR, Mortier GR, Cremers CW. Stickler syndrome type I and Stapes ankylosis. Int J Pediatr Otorhinolaryngol 2004; 68: 1573-1580.

31 Rose PS, Ahn NU, Levy HP, Ahn UM, Davis J, Liberfarb RM et al. Thoracolumbar spinal abnormalities in Stickler syndrome. Spine 2001; 26: 403-409.

32 Al Kaissi A, Klaushofer K, Grill F. Osteochondritis dissecans and Osgood Schlatter disease in a family with Stickler syndrome. Pediatr Rheumatol Online J 2009; 7: 4.

33 Rai A, Wordsworth P, Coppock JS, Zaphiropoulos GC, Struthers GR. Hereditary arthro-ophthalmopathy (Stickler syndrome): a diagnosis to consider in familial premature osteoarthritis. Br J Rheumatol 1994; 33: 1175-1180.
34 Donoso LA, Edwards AO, Frost AT, Ritter R, Ahmad NN, Vrabec $\mathrm{T}$ et al. Identification of a stop codon mutation in exon 2 of the collagen 2A1 gene in a large Stickler syndrome family. Am J Ophthalmol 2002; 134: 720-727.

35 Donoso LA, Edwards AO, Frost AT, Ritter III R, Ahmad N, Vrabec $\mathrm{T}$ et al. Clinical variability of Stickler syndrome: role of exon 2 of the collagen COL2A1 gene. Surv Ophthalmol 2003; 48: 191-203.

36 Richards AJ, Martin S, Yates JRW, Baguley DM, Pope FM, Scott JD et al. Variations in the vitreous phenotype of Stickler syndrome can be caused by different amino acid substitutions in the $X$ position of the type II collagen Gly-X-Y triple helix. Am J Hum Gent 2000; 67: 1083-1094.

37 Winterpacht A, Hilbert M, Schwarze U, Mundlos S, Spranger J, Zabel BU. Kniest and Stickler dysplasia phenotypes caused by collagen type II gene (COL2A1) defect. Nat Genet 1993; 4: 323-326.

38 Ang A, Ung T, Puvanachandra N, Wilson L, Howard F, Ryalls $\mathrm{M}$ et al. Vitreous phenotype: a key diagnostic sign in Stickler syndrome types 1 and 2 complicated by double heterozygosity. Am J Med Genet 2007; 143: 604-607.

39 Richards AJ, Laidlaw M, Whittaker J, Treacy R, Rai H, Bearcroft $\mathrm{P}$ et al. High efficiency of mutation detection in type 1 Stickler syndrome using a two stage approach: vitreoretinal assessment coupled with exon sequencing for screening COL2A1. Hum Mutat 2006; 27: 696-704.

40 Goldblatt J, Behari D. Unique skeletal dysplasia with absence of the distal ulnae. Am J Med Genet 1978; 28: 625-630.

41 Vanek J. Spondyloperipheral dysplasia. J Med Genet 1983; 20: 117-121.

42 Harel T, Rabinowitz R, Hendler N, Galil A, Flusser H, Chemke J et al. COL11A2 mutation associated with autosomal recessive Weissenbacher-Zweymuller syndrome: molecular and clinical overlap with otospondylomegaepiphyseal dysplasia (OSMED). Am J Med Genet 2005; 132A: 33-35.

43 Vuoristo MM, Pappas JG, Jansen V, Ala-Kokko L. A stop codon mutation in COL11A2 induces exon skipping and leads to non-ocular Stickler syndrome. Am J Med Genet A 2004; 130A: 160-164.

44 Knobloch WH, Layer JM. Retinal detachment and encephalocele. J Pediat Ophthalmol 1971; 8: 181-184.

45 Sertie AL, Quimby M, Moreira ES, Murray J, Zatz M, Antonarakis SE et al. A gene which causes severe ocular alterations and occipital encephalocele (Knobloch syndrome) is mapped to 21q22.3. Hum Mol Genet 1996; 5: 843-847.

46 Sertie AL, Sossi V, Camargo AA, Zatz M, Brahe C, PassosBueno MR. Collagen XVIII, containing an endogenous inhibitor of angiogenesis and tumor growth, plays a critical role in the maintenance of retinal structure and in neural tube closure (Knobloch syndrome). Hum Mol Genet 2000; 9: 2051-2058.

47 Billington BM, Leaver PK, McLeod D. Management of retinal detachment in the Wagner-Stickler syndrome. Trans Ophthalmol Soc UK 1985; 104: 875-879.

48 Brown MB, Graemiger RA, Hergersberg M, Schinzel A, Messmer EP, Niemeyer $G$ et al. Genetic linkage of Wagner disease and erosive vitreoretinopathy to chromosome 5q13-14. Arch Ophthalmol 1995; 113: 671-675. 
49 Miyamoto T, Inoue H, Sakamoto Y, Kudo E, Naito T, Mikawa $\mathrm{T}$ et al. Identification of a novel splice site mutation of the CSPG2 gene in a Japanese family with Wagner syndrome. Invest Ophthalmol Vis Sci 2005; 46: 2726-2735.

50 Meredith SP, Richards AJ, Flanagan DW, Scott JD, Poulson AV, Snead MP. Clinical characterisation and molecular analysis of Wagner syndrome. Br J Ophthalmol 2007; 91: 655-659.
51 Wight TN. Versican: a versatile extracellular matrix proteoglycan in cell biology. Curr Opin Cell Biol 2002; 13: 617-623.

52 Horton WA, Hecht JT. Skeletal Dysplasias,

Chondrodysplasias: Disorders of Cartilage Matrix Proteins. In: Royce PM, Steinmann B (eds). Connective Tissue and Its Heritable Disorders: Molecular, Genetic, and Medical Aspects. John Wiley \& Sons, Inc.: Hoboken, NJ, 2003, pp 909-937. 